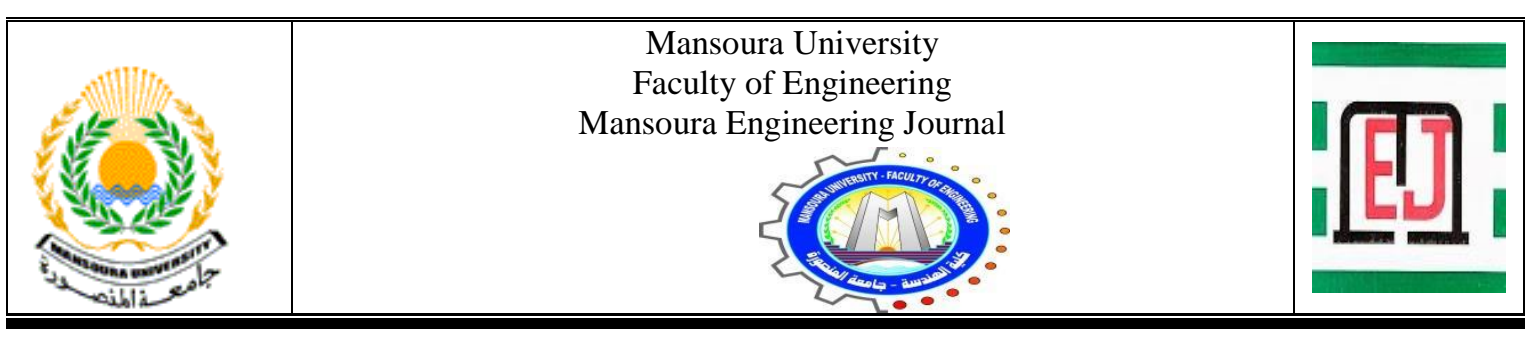

\title{
Evaluation of the Safety of Flexible Pavement using Skid Resistance Measurements
}

\author{
Mokhtar F. Ibrahim, Ahmed AbdELazim M.Ali, Abdelzaher E. Mostafa and A. Abdelghany M
}

\begin{tabular}{|lrr|}
\hline \multicolumn{2}{|l|}{ KEYWORDS: } \\
Skid & Resistance & - \\
Asphalt & Pavement & - \\
British & Pendulum \\
Number & (BPN) & - \\
Pavement & Contaminants \\
- & Reclaimed & Asphalt \\
Pavement & RAP). \\
& \\
& \\
& \\
\end{tabular}

\begin{abstract}
Skid resistance is one of the important parameters used in asphalt pavement characterization. Also, recently with wide extension in roads network over the world and high vehicles speed which lead to high record in accident rates. One of the accident causes is inadequate skid resistance. Various factors affect the skid resistance; some of these are material properties, vehicle speed, surface condition, pavement age, climate and contaminant type. Therefore, this study represents the effect of various contaminants on the skid resistance of asphalt pavement mixes. Two types of asphalt mixes were used; the first was fresh mix, while the second was reclaimed asphalt pavement (RAP) mix. The selected contaminants were water, lube oil and sand. Laboratory tests were performed for hot mix asphalt during (140 days for fresh and 75 days for Rap) and temperature variation range of $\left(\mathbf{1 0 - 3 3}^{0} \mathrm{C}\right.$. British Pendulum (BP) Tester was used to identify the skid resistance values. The test was carried out of leveled flexible pavement slabs for both fresh and reclaimed mixes. Two sections for every slab were tested for both control and contaminated slab. The results indicated that British Pendulum Number (BPN) values changed by the change of contaminant type. Also, it was observed that the lowest values of BPN were investigated using lube oil compared to water and sand. Finally, Significant changes have been occurred in BPN values by the variation in mix type.
\end{abstract}

\section{INTRODUCTION}

$\mathrm{A}$ SPHALT mixes are widely used in both highways and airfields compared to rigid pavement; more than $90 \%$ of roads are constructed using asphalt

Received: (14 January, 2021) - Revised: (24 March, 2021) - Accepted: (28 March, 2021)

Mokhtar F. Ibrahim, Lecturer of Highway and Traffic Engineering, Civil Engineering, High Institute of Engineering - El Shorouk Academy, Egypt.(Email: mokhtargendy91@gmail.com).

Corresponding Author: Ahmed AbdELazim M.Ali, M.sc Student, Civil Engineering, High Institute of Engineering- El Shorouk Academy, Egypt.

(E-mail: Ahmedabdelazim340@gmail.com).

Abdelzaher E. Mostafa, Professor. of Highway and Airport Engineering, Public Works Department, Faculty of Engineering, Helwan University, Egypt. (E-mail: E-mail: Zaher292@yahoo.com).

A. abdelghany M, Lecturer of Highway and Traffic Engineering, Civil Engineering, Public Works Department, Faculty of Engineering, Helwan University,Egypt.(E-mail: traffic_roads@yahoo.com). mixes [1,2]. Generally, pavement construction should be characterized by quality, economic, and safety. Traffic safety and efficiency of the road system had increasing importance for management agencies. Thus, friction evaluation has become an important tool in the management of pavement surfaces [3]. The main concern of any transportation system is achieving the safety of highways network. There are several causes of road accidents; one of these is the sliding texture of pavement surface. Uncontrolled skidding due to inadequate surface friction and poor visibility due to splash and spray have been found to be the two primary causes of wet weather crashes with skidding alone contributing to $15 \%$ to $35 \%$ of all wet weather accidents [4]. Providing an adequate texture depth has been conducted by Forster S.W. [5] to improve pavement friction test results at high speeds and reduce crash rates on high speed facilities. Acceptable pavement surface against sliding mainly depend on both of mix components and environmental conditions. Gradation and properties of aggregate affected the friction between pavement surface and vehicle tires [5, 6]. Frictional resistance of the wearing course 
was improved when angular aggregates were used in asphalt mixes [6]. That leads to an increase in fractured faces of the coarse aggregate, which improve stability of the mixture. Also, some of standards specify a minimum surface texture depth of the pavement surface to ensure adequate macrotexture for effective surface drainage needed for wet weather driving [6,7]. Also, the bitumen content has a major effect on surface sliding. In addition, the environmental conditions as rainfall and temperature changes as well as other contaminants as lube oils and sand have an influence on skid resistance [8]. Thus, some of these contaminants such as lube oil, water and sand were tested using different mixes (Fresh and RAP)

pavement texture can be classified into three categories according to wavelength of its components, Microtexture, macrotexture, and Megatexture [9]. The correlation between the British Pendulum Number (BPN) and surface texture depth has been investigated by Yager and Buhlmann [10]. The study noted that the variation of BPN is independent on surface texture depth. In contrast, Liu et al. [11] noted that BPN depends on both surface Microtexture and macrotexture. As A laboratory test for measuring low-speed friction of pavement surface was conducted by using British pendulum tester. Experiments were made on different size and shape of transverse and longitudinal grooved surfaces to find their skid resistances. The study noted that the microtexture should be taken into consideration when examining macrotexture effect on skid resistance using BPT [12]. Ahammed and Tighe [13] studied the effect of change in pavement texture on the skid resistance. Both of pavement texture and skid resistance were recorded using the data collected from nine locations. Pavement surface texture was measured using the sand patch method and a high speed texture laser, while skid resistance values were measured using a $\mathrm{BP}$ and a skid trailer. The results indicated that, aggregate quality was the major factor that govern surface skid resistance values. Therefore, in the study, the effect of using different contaminants with the variation of both time and temperature for different mixes (Fresh and RAP) was examined.

\section{MATERIALS}

The experimental tests were carried out using wearing surface slabs dense graded mix (4C) for both fresh and recycled mixes. These slabs were tested using British Pendulum Tester (BPT) to determine the skid resistance number subjected to various contaminants. Materials properties used in asphalt slabs are presented in the following sections.

\section{A. Aggregate}

The coarse and fine aggregates used in this research are crushed stones from dolomite. The physical properties and gradation of the used aggregate for both fresh and recycled mixes are shown in Tables (1) and (2). The mix gradation of the aggregate is presented in Table (3). It should be mentioned that the ratio of recycled to fresh aggregate was 30:70 in RAP mixes.

TABLE I

AGgREGATE PROPERTIES FOR FRESH MIXES

\begin{tabular}{|c|c|c|c|c|c|}
\hline Property & $\begin{array}{c}\text { AASHTO } \\
\text { DESIGNATION No. }\end{array}$ & $\begin{array}{c}\text { Coarse Aggregate } \\
\text { Size (1) }\end{array}$ & $\begin{array}{c}\text { Coarse } \\
\text { Aggregate } \\
\text { Size (2) } \\
\end{array}$ & $\begin{array}{c}\text { Fine } \\
\text { Aggregate }\end{array}$ & AASHTOLimits \\
\hline $\begin{array}{l}\text { Los Angeles } \\
\text { abrasion \% }\end{array}$ & AASHTO 96-(2006) & 27.20 & 31.4 & ------ & $40 \mathrm{Max}$ \\
\hline Bulk (S.G) & AASHTO (85-77) & 2.411 & 2.505 & 2.713 & -------- \\
\hline $\begin{array}{c}\text { Saturated and } \\
\text { dry surface } \\
\text { (S.G) } \\
\end{array}$ & AASHTO (85-77) & 2.502 & 2.562 & ------ & -------- \\
\hline $\begin{array}{c}\text { Apparent } \\
(S . G)\end{array}$ & AASHTO (85-77) & 2.652 & 2.655 & ------ & --------- \\
\hline $\begin{array}{c}\% \text { Water } \\
\text { absorption }\end{array}$ & AASHTO (85-77) & 3.80 & 2.25 & ------ & $5 \operatorname{Max}$ \\
\hline
\end{tabular}

TABLE 2

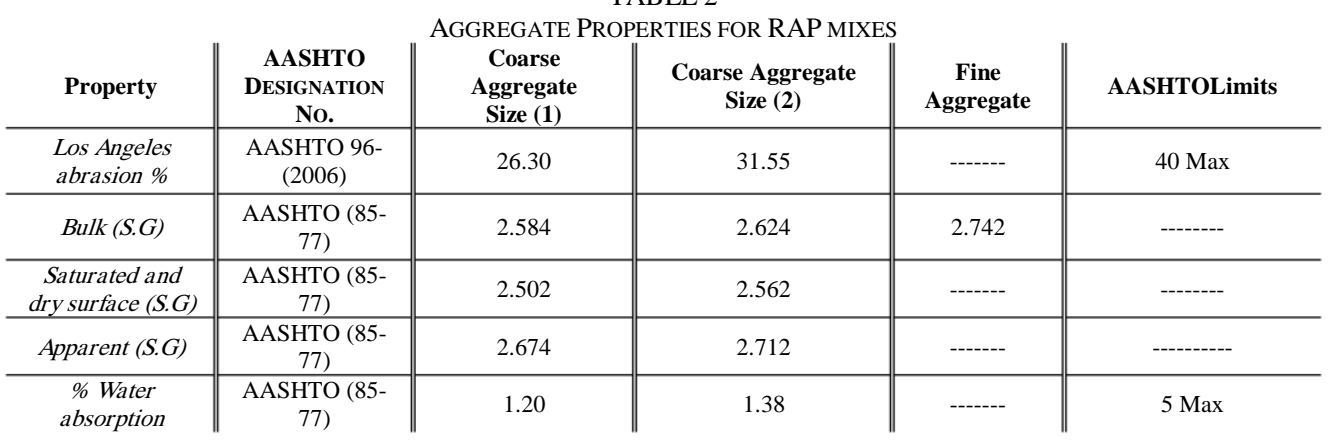


TABLE 3

AGGREGATE GRADATION

\begin{tabular}{|c|c|c|c|c|}
\hline \multirow{2}{*}{ Sieve Size (Inch) } & \multirow{2}{*}{ Sieve Size $(\mathbf{m m})$} & \multirow{2}{*}{$\begin{array}{c}\text { Design Mix Gradation } \\
\% \text { Passing }\end{array}$} & \multicolumn{2}{|c|}{ Specification Limits (4C) } \\
\hline & & & Lower & Upper \\
\hline $1 "$ & 25.40 & 100 & 100 & 100 \\
\hline $3 / 4 "$ & 19.00 & 96.90 & 80 & 100 \\
\hline $1 / 2^{\prime \prime}$ & 12.70 & 82.30 & ---- & ---- \\
\hline $3 / 8^{\prime \prime}$ & 9.50 & 74.80 & 60 & 80 \\
\hline No. (4) & 4.75 & 58.20 & 48 & 65 \\
\hline No. (8) & 2.36 & 38 & 35 & 50 \\
\hline No. (16) & 1.19 & 49.70 & ---- & ---- \\
\hline No. (30) & 0.60 & 20.60 & 19 & 36 \\
\hline No. (50) & 0.30 & 13.70 & 13 & 23 \\
\hline No. (100) & 0.15 & 12.50 & 7 & 15 \\
\hline No. (200) & 0.075 & 7.0 & 3 & 8 \\
\hline
\end{tabular}

\section{B. Asphalt Binder}

The asphalt cement used in this study is obtained from Suez with grade of 60/70. Its specific gravity is 1.02 which widely used in construction in Egypt. The consistency properties tests of Asphalt Cement (AC) were conducted and the results are shown in Table (4).

TABLE 4

AsPhalt CEMENT PRoperties

\begin{tabular}{c||c||c||c} 
Property & $\begin{array}{c}\text { AASHTO } \\
\text { DESIGNATION } \\
\text { No. }\end{array}$ & Result & $\begin{array}{c}\text { Specifications } \\
\text { Limits }\end{array}$ \\
\hline $\begin{array}{c}\text { Penetration at } 25 \text { o } \\
\text { c, 0.1mm }\end{array}$ & T- 49 & 64 & $60-70$ \\
\hline $\begin{array}{c}\text { Rotation Viscosity } \\
\text { at 135 }{ }^{\circ} \text { c, Cst. }\end{array}$ & T- 201 & 340 & $\geq 320$ \\
\hline Flash point, o c & T-48 & 264 & $\geq 250$ \\
\hline Softening Point, ${ }^{\circ} \mathrm{c}$ & T-53 & 49 & $45-55$
\end{tabular}

\section{C.Marshall Test}

The first step in the Marshall test is determining the optimum bitumen content (OBC). In this research $\mathrm{OBC}$ value for the mixtures (Fresh and RAP) was determined. This value for the control (conventional) mixture was $5.35 \%$, while this value for RAP was $5.10 \%$ which was determined by bitumen extraction test. Also, Marshall Properties for both control and RAP mixtures were determined and reported as shown in Table (5).

TABLE 5

MARShALL TEST RESUltS

\begin{tabular}{c||c||c} 
Property & Control Mix & RAP MIX \\
\hline Stability $(\mathrm{Kg})$ & 1355 & 1453 \\
\hline Flow $[\mathrm{mm}]$ & 2.9 & 2.73 \\
\hline Air voids $(\mathrm{VA})(\%)$ & 3.9 & 4 \\
\hline $\begin{array}{c}\text { Unit } \text { Weight }_{\left(\mathrm{gm} / \mathrm{cm}^{3}\right)} \\
(\mathrm{gMA} \%)\end{array}$ & 2.335 & 2.433 \\
\hline OBC\% & 15.8 & 15.9 \\
\hline & 5.35 & 5.1
\end{tabular}

\section{Contaminants}

Three types of contaminants were used in this study to identify the behavior of asphalt pavement skid resistance against these contaminants. The first one was pure water, while the second was lube oil with viscosity grade $5 \mathrm{~W} 30$ and the third was sand dust which passed sieve no 200.

\section{Experimental Procedure And Testing}

The main aim of the study was the evaluation of the effect of contaminant types on the skid resistance of asphalt pavement. For this purpose, the experimental program consists of preparing four slabs; the first was the base specimen and the other three were for contaminants testing. As well as the tested slabs were divided into two sections to identify two values of skid resistance for the same slab for both fresh and RAP mixes. Figure (1) shows the tested slabs with various contaminants. Skid resistance number (BPN) values for all slabs can be determined using British Pendulum tester (BPT) as described in the following lines.

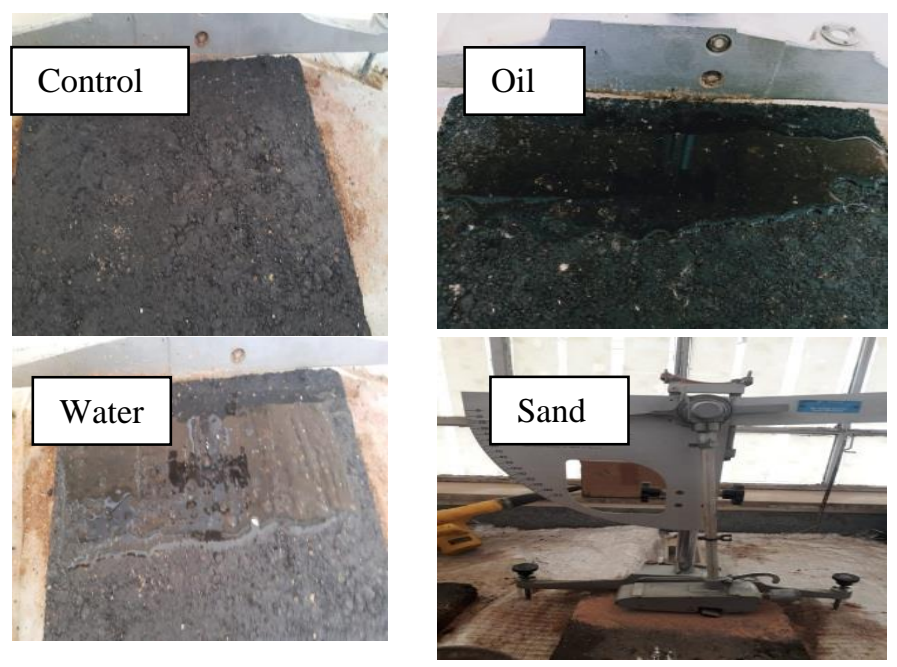

Fig. 1. - Asphalt Concrete Slabs with Contaminants.

\section{British Pendulum Tester (BPT)}

The British Pendulum Tester (BPT) is a device used in skid resistance measurement which is described as British Pendulum Number (BPN) in accordance with BS EN 13036- 
4:2011 [14]. BPN values are determined by measuring the loss of energy when the edge of a rubber slider is propelled over a pavement surface specimen [15]. The procedure of BPT in skid resistance depends on the Microtexture of the pavement surface [15] and it can be used in both field and laboratory tests. The factors affected surface texture can be summarized as, type and size of the used aggregate, asphalt cement content and properties, and environmental conditions. Thus, in this study surface texture takes several forms by adding water, sand dust, and lube oil as environmental conditions. Also, the effect of the test period and temperature variation on skid resistance was examined in this paper. Figure (2) shows the BPT device. BPT includes a slider, which is spring-loaded and made of standard rubber mounted to the end of a pendulum arm. When the pendulum arm is released from a horizontal position, the slider assembly passes over the test surface and the energy loss is measured by the reduction in length of the upswing using a calibrated scale.

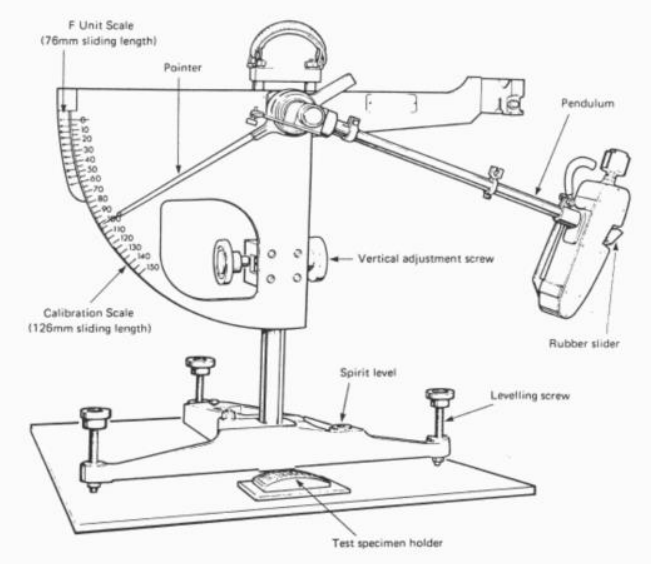

Fig.2. - British Pendulum Device, (Nanyang Technological University, undated)

\section{RESUlts AND DISCUSSIONS}

This study investigated the values of skid resistance (BPN) number for the tested specimens (fresh and RAP) as presented in Tables (6) and (7). The following lines discuss in details the results for both fresh and RAP mixes for various contaminants (water, oil and sand).

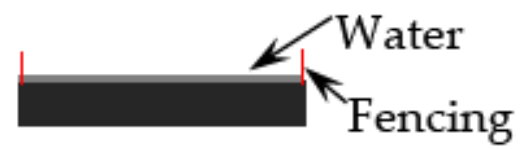

Fig. 3:- Asphalt Slab Preparation under Water Contaminant

Effect of Water on Skid Resistance Number (BPN)

The preparation of the tested slab is carried out to keep the depth of water on the slab uniform as 1 to $2 \mathrm{~mm}$ as shown in Figure (3). The temperature during the test period has been recorded. The effect of water on skid resistance of asphalt slabs is shown in Figures $(4,5)$ and Tables $(6,7)$ for both fresh and Rap mixes. The Results indicated that a significant change occurred by adding water. Referring to the results in Figures $(4,5)$, it was found that the BPN values decreased during the test period for both fresh and Rap mixes. While the reduction in BPN for Rap mixes was higher than those for fresh mixes. The reduction in BPN values may be due to the smooth layer formed on the slab surfaces which lead to the reduction in friction between the tester and pavement surface. In addition, the variation in BPN for fresh and RAP mixes may be due to the variation in surface texture. Also, two sections for the same slab have been investigated as shown in Figures $(4,5)$. It can be noted that the values of skid resistance (BPN) of section (I) slightly changed compared to these values of section (II). This difference may be due to the variation in surface texture between two sections. Finally, the main conclusion from this study is the effect of the test period as BPN values decreased by an increase in test period. As presented in Table (6), the lowest value of BPN number recorded after 140 days.

TABLE 6

SKID RESISTANCE NUMBER/BPN AT VARIOUS CONTAMINANTS FOR FRESH MIXES ASPHALT

\begin{tabular}{|c|c|c|c|c|c|c|c|c|c|}
\hline \multicolumn{2}{|c|}{ Contaminants } & \multicolumn{2}{|c|}{ Control Slab (C.S) } & \multicolumn{2}{|l|}{ Water } & \multicolumn{2}{|l|}{ Sand Dust } & \multicolumn{2}{|l|}{ Lube Oil } \\
\hline PERIOD & SECTION & SECTION I & SECTION II & SECTION I & SECTION II & SECTION I & SECTION II & SECTION I & SECTION II \\
\hline \multicolumn{2}{|c|}{1 day $(23)^{\circ} \mathrm{C}$} & 89 & 90 & \begin{tabular}{|l|}
83.33 \\
\end{tabular} & 83.00 & 65 & 70 & 31.66 & \begin{tabular}{|l|}
34.33 \\
\end{tabular} \\
\hline \multicolumn{2}{|c|}{8 days $(23)^{\circ} \mathrm{C}$} & 88 & 88 & 83.33 & 83.33 & 63.33 & 61.66 & 31.66 & 28.33 \\
\hline \multicolumn{2}{|c|}{15 days $(19)^{\circ} \mathrm{C}$} & 88 & 87 & 83.33 & 83.33 & 58.34 & 61.66 & 23.33 & 21.66 \\
\hline \multicolumn{2}{|c|}{30 days $(17)^{\circ} \mathrm{C}$} & 87 & 86 & 81.66 & 83.33 & 58.33 & 58.33 & 18.33 & 16.66 \\
\hline \multicolumn{2}{|c|}{50 days $(12)^{\circ} \mathrm{C}$} & 86 & 87 & 78.33 & 81.66 & 58.33 & 56.66 & 15.00 & 16.66 \\
\hline \multicolumn{2}{|c|}{80 days $(10)^{\circ} \mathrm{C}$} & 85 & 86 & 78.33 & 80.00 & 56.66 & 56.66 & 11.66 & 15.00 \\
\hline \multicolumn{2}{|c|}{110 days $(27)^{\circ} \mathrm{C}$} & 85 & 85 & 76.66 & 78.33 & 56.66 & 53.33 & 11.66 & 11.66 \\
\hline \multicolumn{2}{|c|}{140 days $(29)^{\circ} \mathrm{C}$} & 84 & 84 & 76.66 & 76.66 & 56.66 & 53.33 & Slab Failed & Slab Failed \\
\hline
\end{tabular}


TABLE 7

SKID RESISTANCE NUMBER/BPN AT VARIOUS CONTAMINANTS FOR RAP

\begin{tabular}{|c|c|c|c|c|c|c|c|c|c|}
\hline \multicolumn{2}{|c|}{ Contaminants } & \multicolumn{2}{|c|}{ Control Slab (C.S) } & \multicolumn{2}{|c|}{ Water } & \multicolumn{2}{|c|}{ Sand Dust } & \multicolumn{2}{|c|}{ Lube Oil } \\
\hline PERIOD & SECTION & SECTION I & SECTION II & SECTION I & SECTION II & SECTION I & SECTION II & SECTION I & SECTION II \\
\hline \multicolumn{2}{|c|}{1 day $(29){ }^{\circ} \mathrm{C}$} & 125 & 124 & 70.66 & 70.66 & 65.66 & 65.66 & 30.66 & 31.33 \\
\hline \multicolumn{2}{|c|}{4 days $(28)^{\circ} \mathrm{C}$} & 125 & 123 & 71 & 70.66 & 64.33 & 65 & 30.33 & 30.66 \\
\hline \multicolumn{2}{|c|}{5 days $(27)^{\circ} \mathrm{C}$} & 124 & 123 & 69 & 69.66 & 62 & 63.66 & 29 & 29.66 \\
\hline \multicolumn{2}{|c|}{8 days $(30)^{\circ} \mathrm{C}$} & 124 & 123 & 69.33 & 69 & 61.66 & 62.33 & 29 & 29.33 \\
\hline \multicolumn{2}{|c|}{18 days $(32)^{\circ} \mathrm{C}$} & 123 & 122 & 69.33 & 69.33 & 61.66 & 62.66 & 29.33 & 29 \\
\hline \multicolumn{2}{|c|}{23 days $(31)^{\circ} \mathrm{C}$} & 122 & 121 & 69 & 68.66 & 61.33 & 61.33 & 28.66 & 28 \\
\hline \multicolumn{2}{|c|}{26 days $(33)^{\circ} \mathrm{C}$} & 122 & 121 & 67.33 & 66 & 59.66 & 60.66 & 25.66 & 26 \\
\hline \multicolumn{2}{|c|}{30 days $(29)^{\circ} \mathrm{C}$} & 122 & 121 & 66 & 67.33 & 60.66 & 59.66 & 26.33 & 25.33 \\
\hline \multicolumn{2}{|c|}{33 days $(30)^{\circ} \mathrm{C}$} & 121 & 120 & 66.33 & 66.66 & 61.66 & 59.33 & 26 & 26.66 \\
\hline \multicolumn{2}{|c|}{51 days $(32)^{\circ} \mathrm{C}$} & 121 & 120 & 65.33 & 65.33 & 62 & 58.66 & 25.66 & 26.33 \\
\hline
\end{tabular}

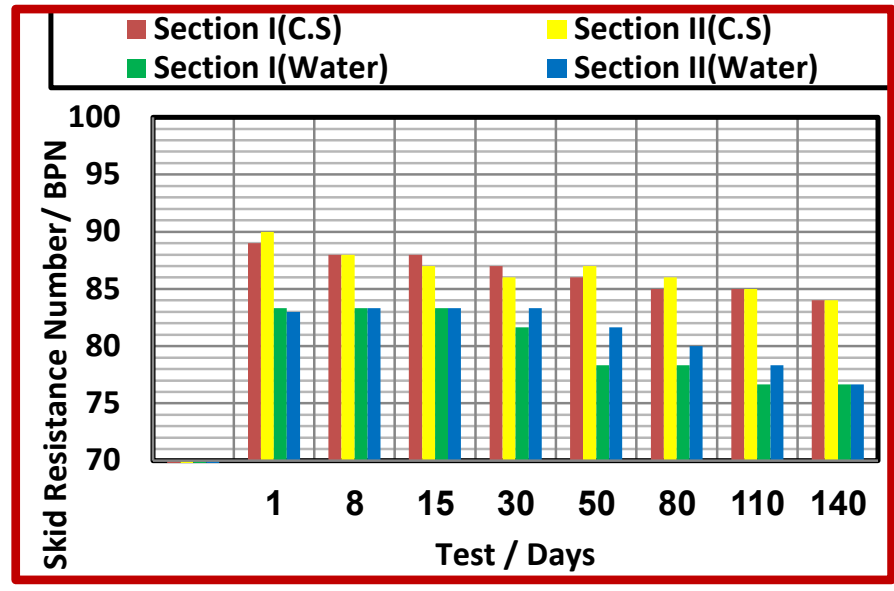

4. Effect of Water on Skid Resistance Number / BPN for Fresh Asphalt Mixes

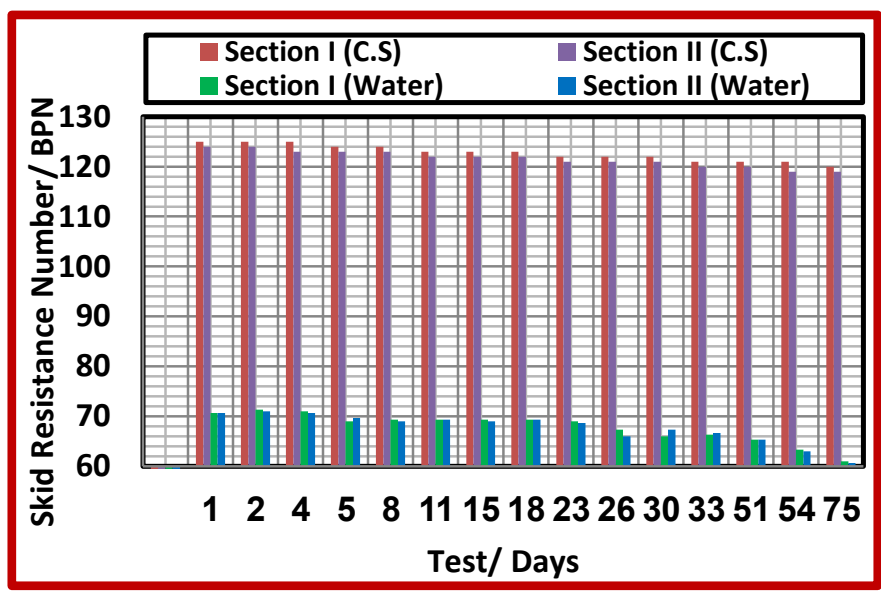

Fig. 5. Effect of Water on Skid Resistance Number / BPN for RAP Asphalt Mixes

\section{Effect of Sand on Skid Resistance (BPN)}

This section presents the effect of sand on skid resistance number (BPN) values of asphalt slabs as shown in Figures (6, $7)$ and Tables $(6,7)$ for both fresh and Rap mixes. The samples preparation is done by spreading the sand contaminant on the asphalt slab surface where the sand on the slabs has a uniform distribution as shown in Figure (1) for both sections (I) and (II). From the results recorded, it can be noted that the contaminant (sand) has a major effect on the skid resistance values as it decreases these values compared to the control samples (without contaminants). Referring to the results in Figures $(6,7)$, it was found that the BPN values decreased during the test period for both fresh and Rap mixes. As well as, it observed that BPN values for fresh mixes were slightly differing than these values for RAP mixes. Also, it should mention that the temperature during the test period has been recorded. The reduction in BPN values may be due to the reduction in friction between the tester and pavement surface due to the presence of sand on the pavement surface. Also, change the test location for the same slab has been investigated as shown in Figures $(6,7)$. It can be noted that the values of skid resistance (BPN) of section (I) slightly changed compared to these values of section (II). This difference may be due to the variation in surface texture between two sections.

Also, if the comparison between the results recorded of water and sand, it can be noted that the effect of sand on the BPN values was higher than the effect of water. The reason may be due to skid resistance of asphalt pavements was affected by sand when its particles involved between the voids of the slab and filled it. The effect of sand on the skid resistance is greater than that of water. 


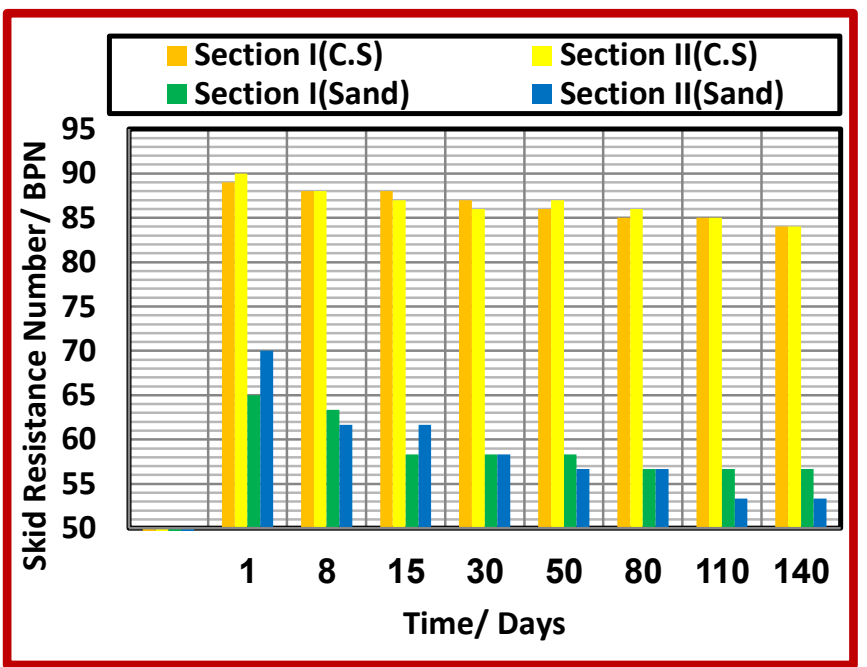

Fig.6. Effect of Sand on Skid Resistance Number / BPN- Fresh Asphalt Mixes

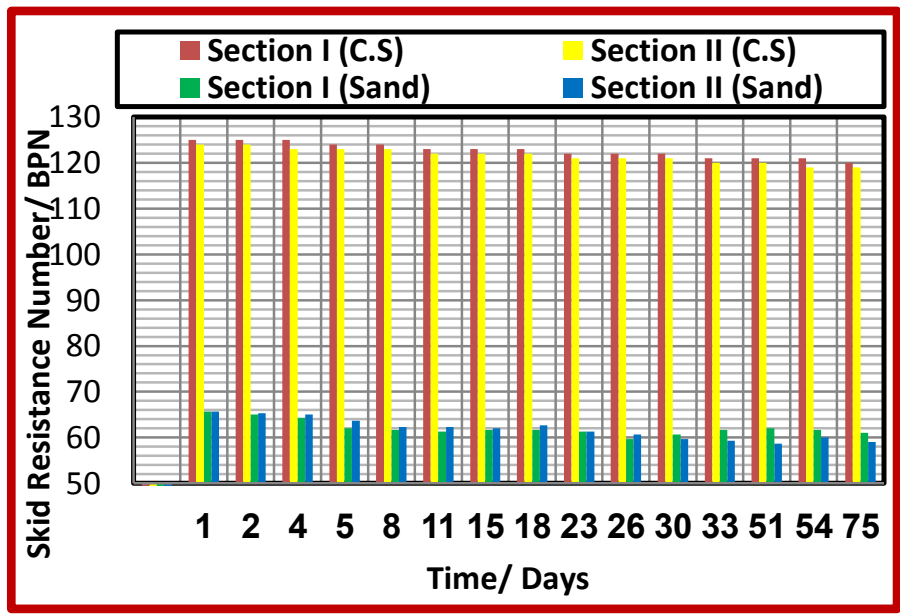

Fig.7.Effect of Sand on Skid Resistance Number / BPN for RAP Asphalt Mixes. differing than these values for RAP mixes. The reduction in BPN values may be due to the reduction in friction between the tester and pavement surface due to the presence of oil on the pavement surface. Also, change the test location for the same slab has been investigated as shown in Figures $(8,9)$. It can be noted that the values of skid resistance (BPN) of section (I) changed compared to these values of section (II). This difference may be due to the variation in surface texture between two sections.

Also, if the comparison between the results recorded of the three contaminants is conducted, it can be noted that the effect of oil on the BPN values was higher than the effect of both of water and sand. That may be due to the presence of oil on the slab surface formed a film of lubrication material which penetrate into the pavement and increasing the sliding action. In addition, the presence of oil on the slab surface leads to the penetration of oil into the slab which making a weakness of the tested pavement and the pavement failed as presented in Table (6) for slabs after 140 days.

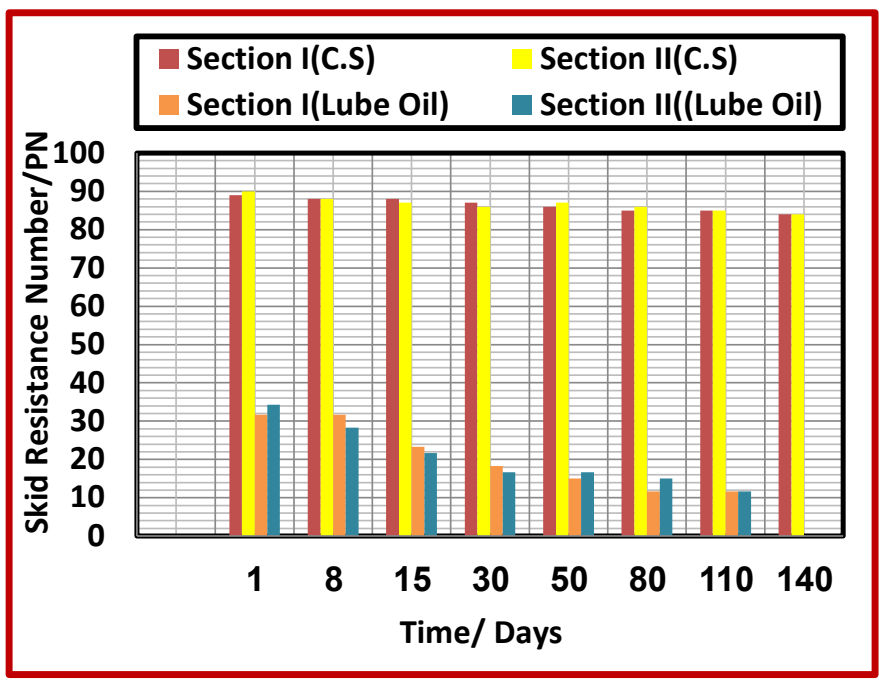

Fig.8. Effect of Lube oil on Skid Resistance Number / BPN- Fresh Asphalt Mixes

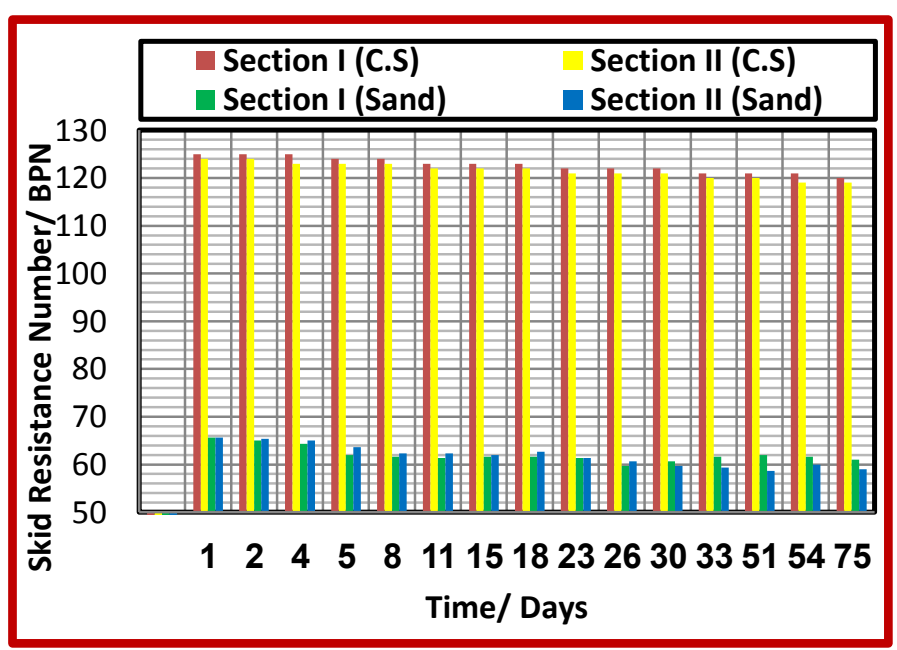

Fig.9. Effect of Lube oil on Skid Resistance Number / BPN- RAP Asphalt Mixes

\section{Effect of Lube Oil on Skid Resistance (BPN)}

The influence of oil on the skid resistance (BPN) values for both fresh and RAP asphalt mixes is presented and analyzed in the following lines. Also, Figures $(8,9)$ and Tables $(6,7)$ show the values of BPN for both fresh and RAP asphalt mixes. The preparation of tested samples is as same as those for water contaminant samples. It summarized by keeping the depth of oil on the sample surface is uniform with depth of $1-2 \mathrm{~mm}$ as shown in Figure (1). The tested pavement slabs consist of two sections (I) and (II) for both fresh and RAP asphalt mixes. The test period for fresh and RAP mixes were 140 and 75 days respectively. From the results obtained, it investigated that the contaminant (oil) has a greatest effect on the skid resistance values as it reduced these values compared to the control samples. Referring to the results in Figures $(8,9)$, it was found that the BPN values decreased during the test period for both fresh and Rap mixes. Also, it observed that BPN values for fresh mixes were slightly 


\section{Conclusion}

The effect of contaminants on skid resistance of asphalt pavements was analyzed. The reasons for the effect of contaminants on skid resistance were discussed. The following conclusions can be summarized: -

1- Skid resistance of asphalt pavements was hardly affected when road surfaces were covered by contaminants.

2- Lube oil has the major effect on the skid resistance of asphalt pavements which make the slab failure and affected on pavement safety. Based on BPN values it is not suitable for roads as a minimum value of BPN is 45 [16].

3- The maintenance agencies of asphalt pavements should remove contaminants in time by reasonable methods to ensure traffic safety when road surfaces were found to be contaminated. But it seems that the effect of water and sand is suitable for roads compared with lube oil which is unsuitable this comes out from the BPN values.

4- The Skid resistance value affected by aging of asphalt pavement which clearly investigated in the study.

5- The friction value for RAP slabs has a lower value than fresh asphalt mix when it is exposed to contaminants that has happened because the aggregate had been processed twice and the shape changed.

6- The values of skid resistance / BPN values for different sections of the same pavement slab slightly changed.

\section{RECOMMENDATIONS}

It is recommended to investigate the effect of using porous asphalt pavement mix on the friction coefficients under different types of contaminants.

\section{REFERENCES}

[1] Pan, P.; Wu, S.; Xiao, Y.; Liu, G., (2015), "A review on hydronic asphalt pavement for energy harvesting and snow melting", Renew. Sustain. Energy Rev., 48, 624-634.

[2] Cui, P.; Wu, S.; Xiao, Y.; Wan, M.; Cui, P., (2015), "Inhibiting effect of Layered Double Hydroxides on the emissions of volatile organic compounds from bituminous materials", J. Clean. Prod., 108 (Pt A), 987-991.

[3] Choubane, B., Holzschuher, C. and Gokhale, S. (2004) Precision of Locked-Wheel Testers for Measurement of Roadway Surface Friction Characteristics. Transportation Research Record: Journal of the Transportation Research Board, 1869, 145-151. [Citation Time(s):5]

[4] Hoerner, T.E., and Smith, K.D., (2002), "High performance concrete pavement: pavement texturing and tire-pavement noise". Federal Highway Administration, USA, Report No. FHWA-DTFH61-01- P00290 .

[5] Forster, S. W., (1989), "Pavement microtexture and its relation to skid resistance", Transportation Research Record, 1215, Transportation Research Board, Washington, D.C., 151-164.

[6] Corley-Lay, J. B., (1998), "Friction and surface texture characterization of 14 pavement test sections in Greenville, North Carolina", Transportation Research Record, 1639, Transportation Research Board, Washington, D.C., 155-161.5.

[7] Kandhal, P. S., Parker, F., Jr., and Bishara, E. A., (1993), "Evaluation of Alabama limestone aggregates for asphalt wearing courses",
Transportation Research Record, 1418, Transportation Research Board, Washington, D.C., 12-21.6.

[8] Bazlamit, S.M.; Reza, F, (2005),"Changes in Asphalt Pavement Friction Components and Adjustment of Skid Number for Temperature", J. Transp. Eng., 131, 470-476.

[9] Henry, J. J. NCHRP Synthesis of Highway Practice 291, (2000), "Evaluation of Pavement Friction Characteristics", TRB, National Research Council, Washington, D.C., 2000.

[10] Yager, T.J., and Buhlmann, F., (1982), "Macrotexture and drainage measurements on a variety of concrete and asphalt surfaces", Pavement Surface Characteristics and Materials, American Society of Testing and Materials, Philadelphia, ASTM STP 763, pp. 16-30.

[11] Liu, Y., Fwa, T.F., and Choo, Y.S., (2004), "Effect of surface macrotexture on skid resistance measurements by the British Pendulum test", Journal of Testing and Evaluation, ASTM International, West Conshohocken, PA, Vol. 32, No. 4. pp. 304-309.

[12] Pancar B.E. and Karaca Z., (2016). "Reliability of British Pendulum Test on Macrotextured Surfaces ", International Journal of Innovation Sciences and Research, Vol.5, No, 01, pp.611-616, January.

[13] Ahammed A.M. and Tighe L.S., (2011), "Asphalt Pavements Surface Texture and Skid Resistance - Exploring the Reality", Canadian Journal of Civil Engineering, December, DOI: 10.1139/111-109.

[14] BS EN 13036-4:2011, "Road and airfield surface characteristics. Test methods. Method for measurement of slip/skid resistance of a surface: The pendulum test.

[15] Lu, Q., Steven, B. (2006), "Friction Testing of Pavement Preservation Treatments: Literature Review", Work Conducted Under Name of Program "Friction Testing of Pavement Preservation Treatments" as part of Maintenance Task Order FY06/07University of California Pavement Research Center. Technical Memorandum: UCPRC-TM-2006-10.

[16] Ibrahim M. A. "Evaluating skid resistance of different asphalt concrete mixes", Department of Civil Engineering, Hashemite University, P.O. Box 150459, Zarqa 13115, Jordan, Building and Environment 42 (2007) $325-329$.

\section{Arabic Title}

$$
\text { تقييم الأمان للرصف الأسفلتى باستخدام قياسات مقاومة الإنزلاق }
$$

\section{Arabia Abstract}

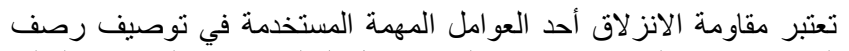

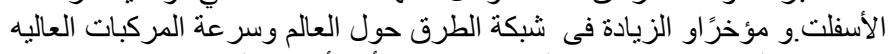

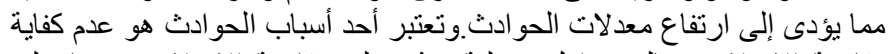

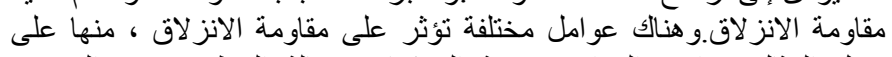

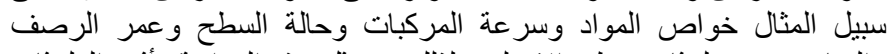

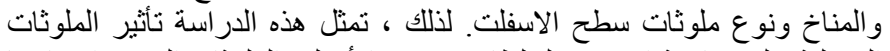

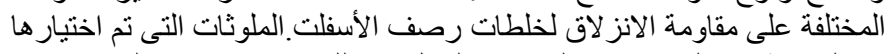

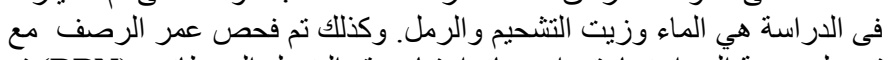

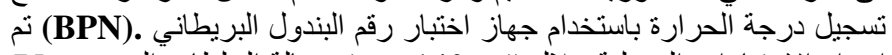

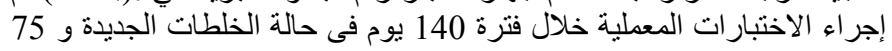

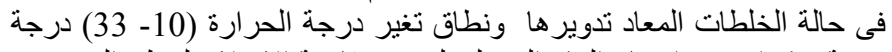

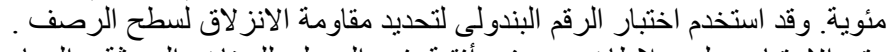

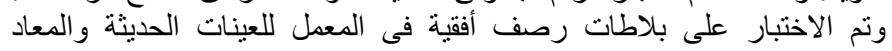

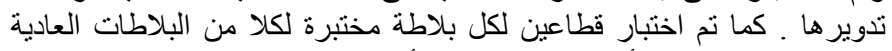

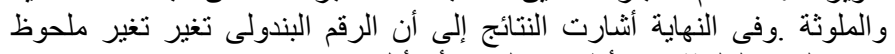

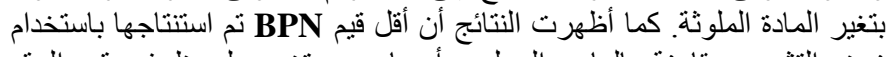

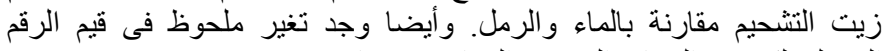
البندولى لكلا من العينات الجديدة و المعاد تذوير ها. 